Tropical Journal of Pharmaceutical Research April 2020; 19 (4): 699-706

ISSN: $1596-5996$ (print); 1596-9827 (electronic)

(C) Pharmacotherapy Group, Faculty of Pharmacy, University of Benin, Benin City, 300001 Nigeria.

\title{
Engelharquinone suppresses lipopolysaccharide-induced inflammation and proliferation of human liver cancer SMCC7721 cells via inhibition of NF-KB and MAPK signaling pathway
}

\author{
Shan Li, Yan Zhang, Aishe Gao*, Yue Zhang, Jiong Zhang \\ Departments of Pathology and Pathophysiology, School of Basic Medicine, Henan University of Chinese Medicine, Zhengzhou \\ 450046, Henan, PR China
}

*For correspondence: Email: ai72wc@163.com

Sent for review: 29 May 2019

Revised accepted: 21 January 2020

\begin{abstract}
Purpose: To investigate the anti-tumor effect of engelharquinone (Eng) on human liver cancer SMCC7721 cells.

Methods: GFP-labeled SMCC7721 cells were used to establish a tumor-bearing mice model used for determination of the effect of different concentrations of Eng on tumor growth. The effect of Eng on SMCC7721 cell viability was determined with MTT assay and cell cycle analysis. The anti-inflammatory effect of Eng on lipopolysaccharide (LPS)-treated SMCC7721 cells were determined through assay of pro-inflammatory cytokines. Besides, the effect of Eng on the expressions of mitogen-activated protein kinase (MAPK), toll-like receptor 4 (TLR4), and nuclear factor kappa B (NF-KB) was determined.

Results: Cell proliferation was suppressed by different concentrations of Eng in LPS-treated SMCC7721 cells. Treatment of nude mice with Eng at high and low doses resulted in significant suppression of tumor growth and marked increases in percentage survival. Treatment of SMCC7721 cells with LPS upregulated the expressions of NF-KB, p65 and MAPK. However, pre-treatment of the cells with Eng suppressed the LPS-induced upregulation of the NF-KB, p65 and MAPK signaling pathways, and further downregulated the production of inflammatory cytokines in SMCC7721 cells. Conclusion: These results indicate that Eng inhibits LPS-induced inflammation and proliferation of human liver cancer SMCC7721 cells via a mechanism involving regulation of NF-KB and MAPK signaling pathways. Thus, Eng has potentials for the clinical management of inflammatory diseases and liver cancer
\end{abstract}

Keywords: Inflammation, Engelharquinone, Lipopolysaccharide, SMCC7721 cells, Toll-like receptor 4

This is an Open Access article that uses a fund-ing model which does not charge readers or their institutions for access and distributed under the terms of the Creative Commons Attribution License (http://creativecommons.org/licenses/by/4.0) and the Budapest Open Access Initiative (http://www.budapestopenaccessinitiative.org/read), which permit unrestricted use, distribution, and reproduction in any medium, provided the original work is properly credited.

Tropical Journal of Pharmaceutical Research is indexed by Science Citation Index (SciSearch), Scopus, International Pharmaceutical Abstract, Chemical Abstracts, Embase, Index Copernicus, EBSCO, African Index Medicus, JournalSeek, Journal Citation Reports/Science Edition, Directory of Open Access Journals (DOAJ), African Journal Online, Bioline International, Open-J-Gate and Pharmacy Abstracts

\section{INTRODUCTION}

Liver cancer constitutes a challenge to public health due to the unpredictability and high mortality associated with it [1, 2]. Approximately
$40 \%$ of liver cancer cases arise from hepatitis or liver injury induced by other reasons; chronic hepatitis is caused by persistent inflammation $[3,4]$. Increasing evidence have shown that chronic inflammation is implicated in the etiologies of carcinogenesis in different organs 
such as colon and liver [4]. Several studies have reported that TLR4 plays a key role in LPSinduced inflammation [5]. The LPS receptor is important in the development of most human tumors such as liver cancer, lung cancer and gastric cancer $[5,6]$. The interaction between TLR4 and MyD88/TAK1, and the activation of MAPK and NF-KB signaling pathways, are stimulated by lipopolysaccharide [7]. Thus, the effective inhibition of TLR4-mediated inflammatory pathway is an important target for drug screening. It is generally accepted in modern clinical medical practice that chemoprevention is a significant strategy for protection against liver cancer [8]. Due to the high safety and potential benefits of plant-derived compounds such as curcumin, resveratrol, and vitamins, they have been widely used as major chemo-preventive agents [9-11].

Engelharquinone (Eng) is a plant which has been demonstrated to possess potent antimycobacterial and antitumor properties [12,14]. It is a major source of naphthoquinone drugs. In China, the roots of Eng have been widely used for prevention of various human cancers, including breast cancer and esophageal cancer. However, not much is known about the antitumor effects of Eng, and the mechanism involved. The present study was designed to investigate the anti-tumor and anti-inflammatory effects of Eng on human liver cancer SMCC7721 cells.

\section{EXPERIMENTAL}

\section{Ethical statement}

All procedures used in this study were carried out in line with international guidelines [15]. The protocols used in the animal study received approval from the Institutional Animal Care and Use Committee at Henan University of Chinese Medicine.

\section{Reagents}

Human liver cancer SMCC7721 cells and DMEM medium were bought from Zhengzhou Yizeng Biotech Company. The culture medium used contained $10 \%$ fetal bovine serum, $10 \mu \mathrm{g} / \mathrm{mL}$ streptomycin and 100 units $/ \mathrm{mL}$ penicillin. Lipopolysaccharide was obtained from SigmaAldrich (Shanghai, China) and prepared in DMEM at a concentration of $100 \mathrm{ng} / \mathrm{mL}$. Engelharquinone (Eng, formula: $\mathrm{C}_{20} \mathrm{H}_{12} \mathrm{O}_{6} ; \mathrm{MW}$ : 348.06338812; CAS: 942502-92-3) (Figure 1 A) was isolated and purified from green walnut husks as previously described by Tianjin Meilun Pharmaceutical Co. Ltd [13, 14]. The purity of
Eng (> $98 \%$ ) was confirmed using high performance liquid chromatography. Engelharquinone (Eng) was dissolved in DMSO to produce a $1 \mathrm{M}$ stock solution.

\section{Animals and drug administration}

Green fluorescent protein (GFP)-labeled SMCC7721 cells were purchased from Shijiazhuang Wankai Bio-Technology Co. Ltd. Male SPF BALB/c nude mice (6 - 8 weeks old) weighing 20 - $25 \mathrm{~g}$ were bought from Animal Centre in Zhengzhou University (Zhengzhou, China). They were raised in specific pathogenfree cages at Henan University of Chinese Medicine at a temperature of $25 \pm 2{ }^{\circ} \mathrm{C}$ in an environment with a 12-h light/12-h dark cycle. The mice were randomly divided into 3 groups: control group, high-dose Eng $(6 \mathrm{mg} / \mathrm{kg})$ group and low-dose Eng (2 mg/kg) group. Then, $150 \mu \mathrm{L}$ of cell suspension in RPMI 1640 containing $2 \times$ $10^{7}$ SMCC7721-GFP cells, was subcutaneously injected into the right axilla area of each mouse. Two weeks before the cancer cell inoculation, the mice in the treatment groups were administered Eng. Tumor growth was observed on the $35^{\text {th }}$ day. Mice in control group were injected with an equivalent volume of SMCC7721-GFP in place of Eng. The growth of tumors was determined in terms of fluorescent intensity using Berthold LB983 real-time in vivo bioluminescence molecular imaging system (Berthold Technologies, Germany).

\section{Cell culture and cell cycle analysis}

The cells were plated in 24-well plates at a density of $1 \times 10^{5}$ cells/well, and pretreated with $150 \mu \mathrm{M}$ Eng for $12 \mathrm{~h}$. Thereafter, they were incubated with or without $10 \mathrm{ng} / \mathrm{mL}$ LPS for $48 \mathrm{~h}$. After drug administration, the cells were incubated with RNase A $(20 \mu \mathrm{g} / \mathrm{mL})$, followed by treatment with propidium iodide $(25 \mu \mathrm{g} / \mathrm{mL})$. Then, the intensities of propidium iodide fluorescence at different stages of the cell cycle were measured using a flow cytometer with an argon laser and $570 \mathrm{~nm}$ band pass filters.

\section{MTT assay and measurement of SMCC7721 cell apoptosis}

Cell viability was determined with MTT assay according to a protocol described in a previous study [15]. Cell apoptosis and cell cycle were determined using flow cytometry (FC), following Annexin V-FITCl and propidium iodide (PI) double staining using eBioscience kits (USA), in line with the manufacturer's protocol. 
ELISA and quantitative real-time polymerase chain reaction (qRT-PCR)

After treatment of SMCC7721 cells with LPS for $48 \mathrm{~h}$, the cells were recovered from culture medium through centrifugation. Then, the major inflammatory cytokines (NO, iNOS, TNF- $\alpha, I L-1 \beta$, IL-6, IL-8, IL-18, CCL-2, CCL-22, HGF, TGF 1 1, TGF 32 , EGFR and NF-KB) were determined using their respective ELISA kits (eBioscience, USA). In addition, the mRNA expression levels of the pro-inflammatory cytokines were determined with qRT-PCR using SYBR Green (Bio-Rad) in ABI PRISM 7900HT detection systems (Applied Biosystems). The primers were designed by Nanjing Jiancheng Biotechnology (Nanjing, China). The PCR procedure was carried out strictly according to the manufacturer's protocol.

\section{Western blot and NF-KB DNA-binding analysis}

Total proteins were extracted with RIPA lysis buffer (Boster Biological Technology, Wuhan, China). Then, BCA protein Assay Kit (Abcam, Cambridge, MA, USA) was used to quantify the proteins. Equal amounts of protein samples were electrophoresed on $10 \%$ SDS-polyacrylamide gels. The separated protein bands were then transferred to polyvinylidene fluoride (PVDF) membrane (Fengxiang Biotechnology, Zhengzhou, China). The PVDF membrane was sealed for $1 \mathrm{~h}$ to block non-specific binding. Then, the membrane was incubated overnight at $4^{\circ} \mathrm{C}$ with primary antibodies for p27, p53, PCNA, Ki67, p21, iNOS, COX-2, TNF- $\alpha$, IL-1 $\beta$, p38, ERK, JNK, NF-KB, IKB, TLR4, MyD88, TAK1 and GAPDH (Abcam, CST), each at a dilution of 1:1000, followed by washing and incubation with secondary antibody for $1 \mathrm{~h}$. Thereafter, the PVDF membrane was washed in methanol, and then transferred into an Invitrogen E-Gel Image system, prior to exposure to chemiluminescent HRP Substrate (Thermo Fisher, MA, USA). The signals were captured using Image Lab Software (Bio-Rad, Shanghai, China). In this assay, GAPDH was used as an endogenous reference.

\section{Immunoprecipitation (IP) assay}

Immunoprecipitation assay was conducted with kits in line with the guideline of the manufacturers. Analyzed was done using Western blot method.

\section{Statistical analysis}

Data are presented as mean \pm SD. Differences between Eng-treated groups and the controls were compared with One-way ANOVA. The
SPSS 19.0 software was used for data collation and statistical analysis. Graph Pad PRISM 7 was used as the mapping software. Dunn's least significant difference test was used to compare amongst different groups. Statistical significance was fixed at $p<0.05$.

\section{RESULTS}

\section{Effect of Eng on cell proliferation}

The effect of different concentrations of Eng (25, $50,75,100,125$ and $150 \mu \mathrm{M}$ ) on the proliferation of LPS-treated SMCC7721 cells was investigated. The results demonstrated that 150 $\mu \mathrm{M}$ Eng decreased the viability of LPS-treated human liver cancer SMCC7721 cells in a timedependent manner (Figure $1 \mathrm{~B}$ ). Likewise, Figure $1 \mathrm{C}$ shows that LPS significantly upregulated the proliferation of the SMCC7721 cells, but this effect was inhibited by treatment with various concentrations of Eng. In this study, the lowest effective inhibitory concentration of Eng in LPStreated cancer cells was $50 \mu \mathrm{M}$. In addition, Annexin V-FITC/PI flow cytometric analyses demonstrated no obvious changes in apoptosis in SMCC7721 cells in LPS- and/or Eng-treated group(s) (Figure $1 \mathrm{D})$. Cell cycle analysis showed that LPS improved cell cycle progression by downregulating cell count in G0/G1 phase, and upregulating cell count in $S$ and G2/M phases in SMCC7721 cells, which effects were partially suppressed by pretreatment of the cells with 150 $\mu \mathrm{M}$ Eng for $12 \mathrm{~h}$ (Figure $1 \mathrm{E}$ ). Moreover, highdose and low-dose Eng treatments of nude mice significantly suppressed tumor growth and increased their percentage survival (Figures $1 \mathrm{~F}$ and $1 \mathrm{G}$ ). It is noteworthy that results from realtime bioluminescence molecular imaging system showed that Eng markedly inhibited tumor volume and growth in vivo, as reflected in decreased fluorescence intensities (Figure $1 \mathrm{H}$ ).

\section{Engelharquinone inhibited mRNA and protein expressions of major inflammatory cytokines}

The effect of Eng on mRNA and protein expressions of NO (iNOS), TNF- $\alpha$, IL-1 $\beta$, IL6, IL8, IL-18, CCL-2, CCL-22, EGFR, TGF $\beta 1$, and TGF $\beta 2$ was determined using ELISA and qRTPCR. The results from ELISA and qRT-PCR are shown on Figure $2 \mathrm{~A}-\mathrm{K}$, and Figures 3A-3J, respectively. The inflammatory cytokines were significantly upregulated in SMCC7721 cells, but were downregulated by pretreatment of the cells with Eng. There was no obvious inhibitory effect on HGF expression. Western blot analysis for p27, p53, PCNA, Ki67, p21, iNOS, COX-2, TNF$\alpha$, and IL-1 $\beta$ also demonstrated that the expressions of the cell proliferative markers 
(PCNA and Ki67) were suppressed by Eng in LPS-treated SMCC7721 cells. The presence of LPS significantly upregulated the cancer eliminator factors p27, p53 and p21 (Figure 4 A). These findings showed that Eng markedly exerted inhibitory effect on the proliferation of SMCC7721 cells.

Engelharquinone suppressed NF-kB, p65 and MAPK pathways in LPS-treated liver cancer SMCC7721 cells

Results from Western blot showed that LPS significantly increased expressions of phosphorylated IKB and NF-kB p65 proteins in SMCC7721 cells in model group. In contrast, pretreatment with Eng downregulated phosphorylated NF-KB and IKB (Figure $4 \mathrm{~B}$ ). Similarly, the inhibitory effect of Eng on MAPK pathways in LPS-treated SMCC7721 cells was investigated. The results demonstrated that LPS stimulated the phosphorylation levels of p38, ERK and JNK.

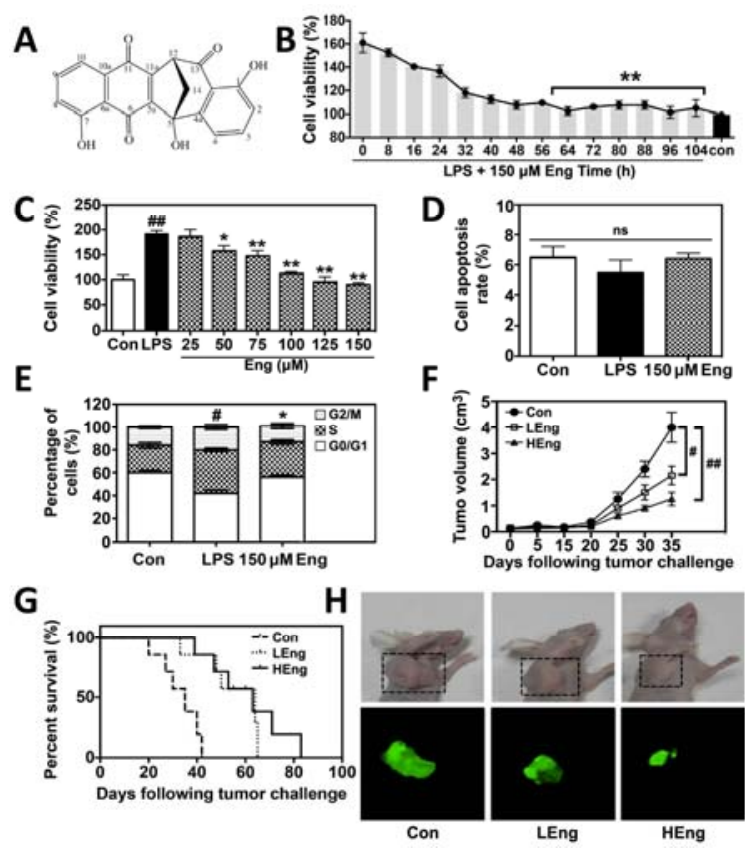

Figure 1: Effect of Eng on the proliferation of LPStreated human liver cancer SMCC7721 cells. (A) Chemical structure of Eng. (B) Effect of treatment with LPS $+150 \mu \mathrm{M}$ Eng on cell viability. (C) Viabilities of cells pretreated with different concentrations of Eng $(25,50$, $75,100,125$ and $150 \mu \mathrm{M}$ ) for $12 \mathrm{~h}$. (D) Effect of treatment with LPS $+150 \mu \mathrm{M}$ Eng on SMCC7721 cell apoptosis, as determined with Annexin- $\mathrm{V}$ and $\mathrm{PI}$ assay. (E) Effect of treatments on cell cycle, as determined using flow cytometry. (F) Tumor growth curves for treated cells and control. (G) Effect of Eng on $\%$ survival of nude mice. $(\mathrm{H})$ Bioluminescence molecular imaging analysis of tumor-bearing mice and tumor volume in terms of relative fluorescence intensity. ${ }^{\#} p<0.05,{ }^{\#} p<0.01$ vs control; ${ }^{*} p<0.05,{ }^{* *} p$ $<0.01$ vs LPS. (ns: not significant; con: control)
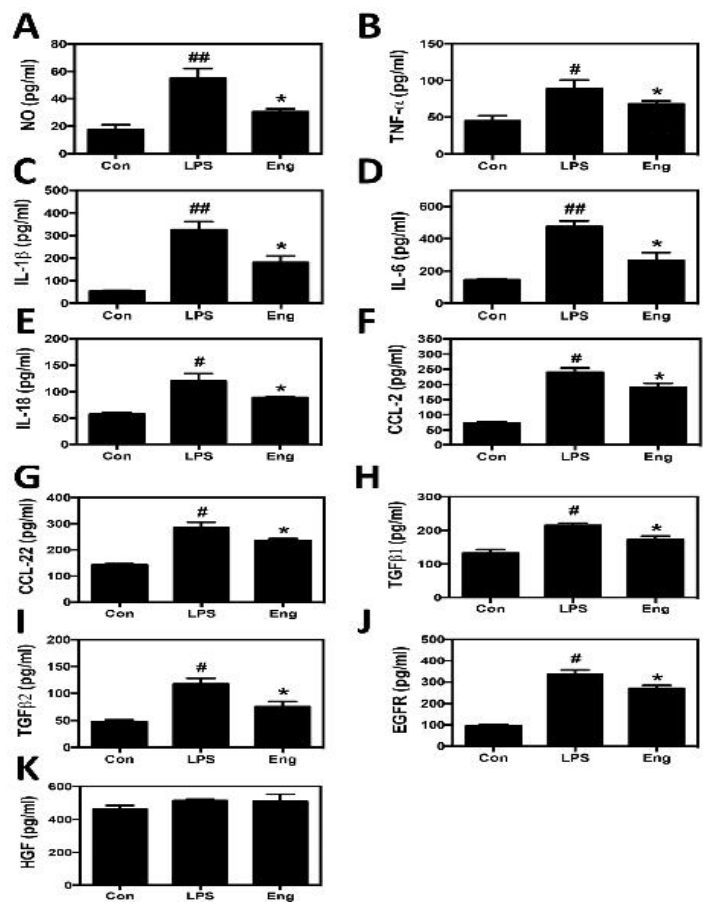

$\mathbf{F}$

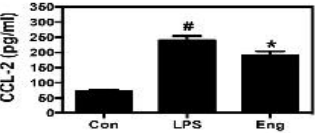

H

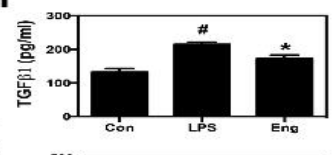

J

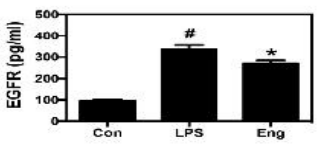

Figure 2: Effect of Eng on the protein expressions of major inflammatory cytokines. (A-K): Following treatment of SMCC7721 cells with LPS for $48 \mathrm{~h}$, the protein expressions of iNOS, TNF- $\alpha$, IL-1 $\beta$, IL-6, IL-8, IL-18, CCL-2, CCL-22, EGFR, TGF $\beta 1$, and TGF $\beta 2$ were determined by ELISA; ${ }^{*} p<0.05 ;{ }^{\#} p<0.01$ vs control; ${ }^{*} p<0.05 ;{ }^{* *} p<0.01$ vs LPS; ns: not significant

However, pretreatment with Eng significantly suppressed the LPS-induced upregulation of these factors. These results are shown in Figures 4 C - E. These findings suggest that LPS upregulated NF-KB and MAPK pathways, leading to expressions of genes for inflammatory factors in SMCC7721 cells. In contrast, pre-treatment with Eng suppressed the NF-KB and p65 pathways, thereby downregulating the generation and release of inflammatory cytokines.

\section{Engelharquinone suppressed the expression of TLR4 and its interactions with MyD88/TAK1 in LPS-treated SMCC7721 cells}

As shown in Figure 5 and Figure 6 A - D, LPS administration led to significant upregulation of TLR4/MyD88 and TLR4/TAK1 protein complexes, as well as marked increases in the downstream factors of NF-kB and p65/lkB. However, as expected, pretreatment of the cells with Eng resulted in significant inhibitory effect on the protein complexes. Therefore, consistent with findings from Western blotting, the results from immunoprecipitation studies indicated that Eng 
treatment inhibited the levels of TLR4/MyD88, TLR4/TAK1 and NF-kB p65/lkB.
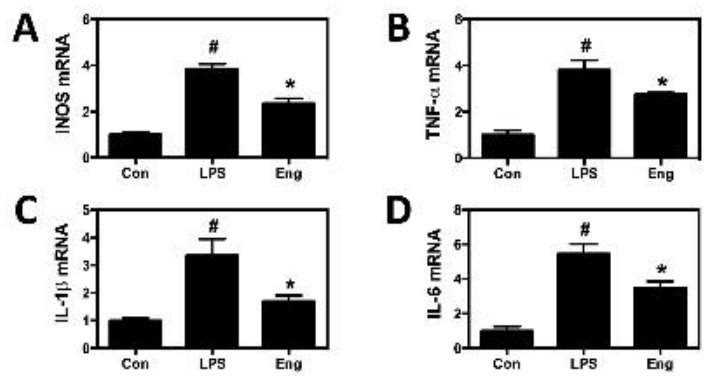

E

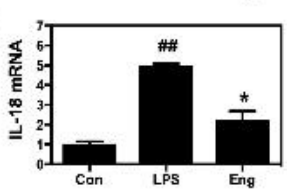

F

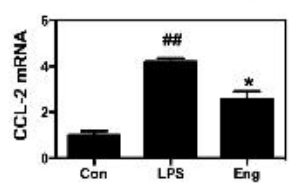

G

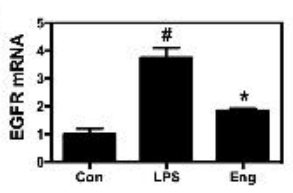

I

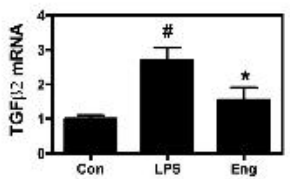

J

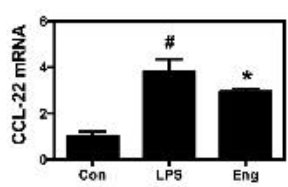

Figure 3: Effect of Eng on the mRNA expression of major inflammatory cytokines. (A-J): After treatment with LPS for $48 \mathrm{~h}$, qRT-PCR was used to assay the mRNA expressions of inflammatory cytokines in SMCC7721 cells; ${ }^{\#} p<0.05,{ }^{\# \#} p<0.01$ vs control; ${ }^{*} p<$ $0.05,{ }^{\star *} p<0.01$ vs LPS; ns: not significant

\section{DISCUSSION}

Increasing evidence have demonstrated that chronic inflammation is a major cause of several cancers, as well as diseases such as hepatitis, lung injury and atrophic gastritis $[3,4,17,18]$. In addition, many inflammatory responses are primarily mediated by the classic NF-kB/MAPK signal pathways via upregulated expressions of inflammatory cytokines $[5,6,19]$. Studies have shown that Eng, a novel natural compound isolated from green walnut husks, exerts potent antitumor effects [12-14]. However, there are no related reports in the literature on whether Eng treatment suppresses inflammatory responses and proliferation in SMCC7721 cells treated with LPS. Thus, the present study was carried out to determine the anti-inflammatory and antiproliferative effects of Eng on human liver cancer SMCC7721 cells stimulated with LPS, and the underlying mechanism(s). Methylthiazolyldiphenyl-tetrazolium bromide (MTT) and cell cycle analysis were used to determine the influence of LPS or/and Eng on cell viability.

A

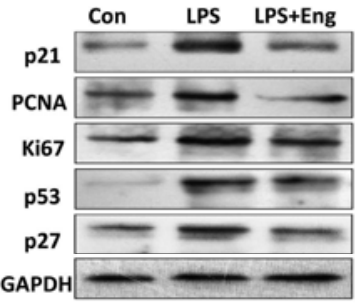

B

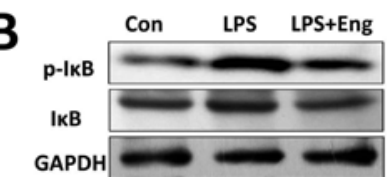

C

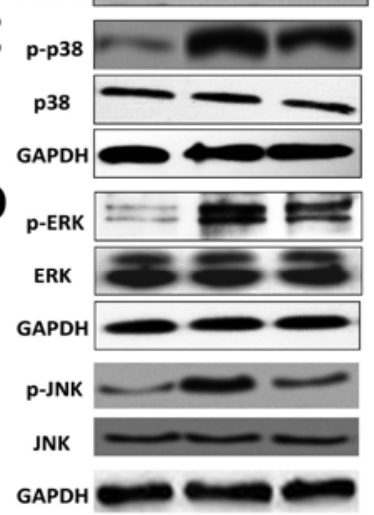

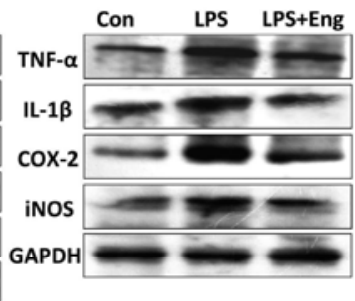
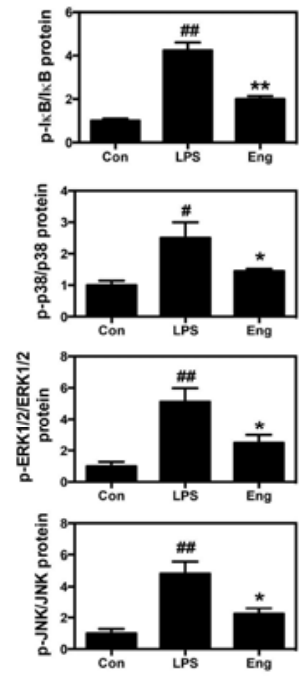

Figure 4: Effect of Eng on the NF-KB and MAPK signaling pathways in LPS-treated SMCC7721 cells. (A) Cell proliferative markers (PCNA and Ki67) and cancer eliminator factors ( $227, \mathrm{p} 53$ and p21) were assayed in LPS-treated SMCC7721 cells using Western blot analysis. At the same time, the expressions of major inflammatory cytokines were determined in SMCC7721 cells. (B-E): Results of Western blotting showing that Eng treatment had a significant effect on the activation of MAPK pathway proteins (ERK1/2, p38 and JNK); ${ }^{\#} p<0.05,{ }^{\#} p<0.01$ vs control; ${ }^{*} p<0.05,{ }^{* *} p<0.01$ vs LPS; ns: not significant

The results showed that various concentrations of Eng $(25,50,75,100,125$ and $150 \mu \mathrm{M})$ suppressed the proliferation of SMCC7721 cells. In previous studies, it was demonstrated that LPS treatment affected the cell cycle and promoted cell proliferation in various cancers [2022].

In this study, LPS promoted cell cycle progression in SMCC7721 cells by decreasing the population of cells in G0/G1 phase, while increasing the population of cells in $S$ and G2/M phases. In contrast, pretreatment with Eng significantly reduced the population of cells in the $S$ and $G 2 / M$ phases. These findings suggest that Eng inhibited cell proliferation by regulating cell cycle. In addition, two different concentrations of Eng suppressed the growth of transplanted 
tumor, and enhanced the percentage survival of mice.
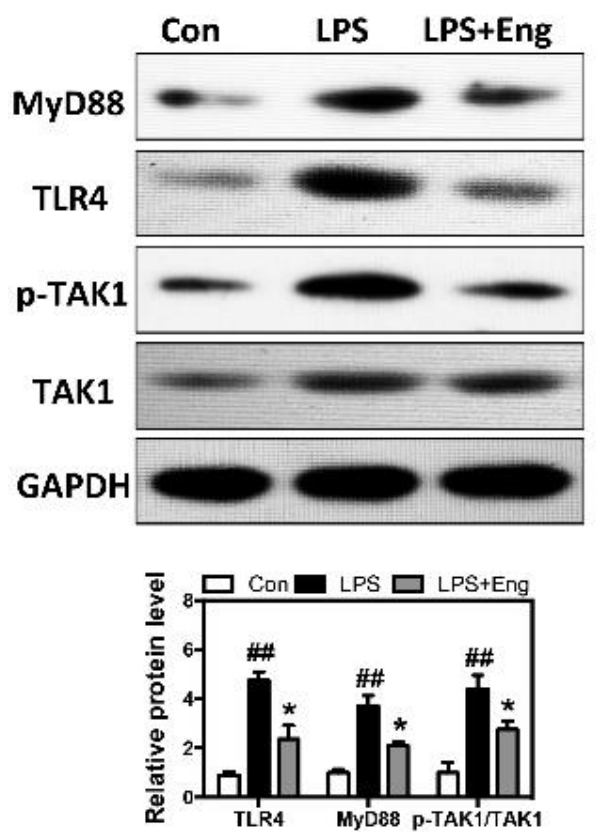

Figure 5: Effect of Eng on the expressions of TLR4, MyD88 and TAK1; ${ }^{\#} p<0.05,{ }^{\#} p<0.01$ vs control; ${ }^{*} p<$ $0.05,{ }^{* *} p<0.01$ vs LPS; ns: not significant

A
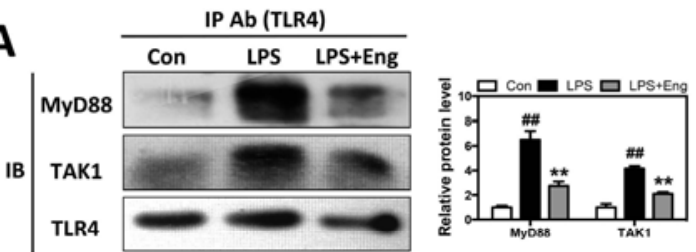

B
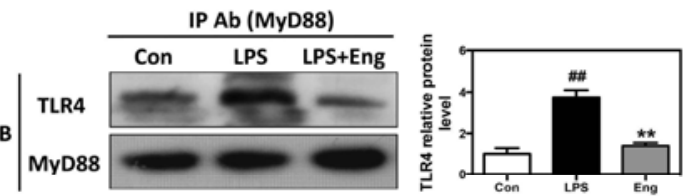

C

IP Ab (NF-KB)
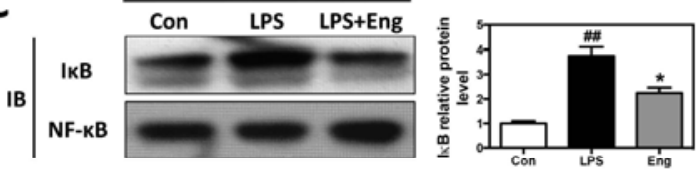

D
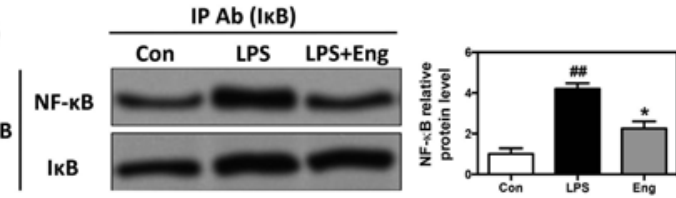

Figure 6: Effect of Eng on the expression of TLR4 and its interactions with MyD88/TAK1 in LPS-treated SMCC7721 cells. (A-D): Immunoprecipitation method was used to determine the protein interactions of TLR4/MyD88, TLR4/TAK1 and NF-kB p65/lkB; ${ }^{\#} p<$ $0.05,{ }^{\#} p<0.01$ vs control; ${ }^{*} p<0.05$, ${ }^{* *} p<0.01$ vs LPS; ns: not significant
Studies have shown that LPS, a very important endotoxin, stimulates inflammatory responses and release of pro-inflammatory cytokines via the TLR4/NF-KB and MAPK signaling pathways [2325]. In present study, it was found that LPS treatment induced proliferation, and upregulated the mRNA and protein expressions of proinflammatory factors in SMCC7721 cells. However, these effects were reversed by pretreatment with Eng for $12 \mathrm{~h}$ through $\mathrm{a}$ mechanism involving inhibition of the NF-KB/ MAPK signaling pathways, as evidenced through the Eng-induced activation of MAPK pathway proteins such as ERK1/2, p38 and JNK. Moreover, the LPS-induced upregulations of phosphorylation of ERK1/2, p38 and JNK in SMCC7721 cells were markedly blocked by administration of Eng. In addition, Eng pretreatment significantly decreased the expression of another important pro-inflammatory pathway i.e. NF-kB pathway, relative to LPStreated cells.

The TLR4/MyD88/TAK1 complex, a key upstream pathway, regulates relative level of inflammation induced by LPS via activation of the NF-kB, p65 and MAPK pathways, which have been regarded as important targets for inhibition by various drugs [26]. Lipopolysaccharide (LPS) significantly activates inflammatory pathways by binding TLR4, and TLR4 mediates activation of NF-KB/MAPK pathway, thereby producing inflammatory responses [27]. Western blot and immunoprecipitation methods were used to determine the involvement of TLR4/MyD88/TAK1 signaling complex in the inhibition of LPSinduced inflammation in SMCC7721 cells by Eng. The results revealed that TLR4 expression was upregulated in LPS-treated group, and it combined with its special adaptor MyD88. Moreover, TAK1, another major member of upstream pathway, was found to be involved in the recruitment of TLR4. This signaling complex was significantly inhibited in the presence of Eng, which showed that CXC195 blocked the combination of TLR4 with MyD88 and TAK1, resulting in deactivation of TLR4 in LPS-treated SMCC7721 cells.

\section{CONCLUSION}

The results obtained in this study suggest that engelharquinone markedly inhibits LPS-induced inflammation and proliferation in SMCC7721 cells through a mechanism involving regulation of the NF-KB and MAPK signaling pathways. Thus, Eng has the potentials to be further developed for the treatment of inflammatory diseases and liver cancer. 


\section{DECLARATIONS}

\section{Acknowledgement}

This work was funded by Doctoral Research Fund of Henan University of Chinese Medicine (no. BSJJ2015-06 and no. BSJJ2018-01) and Key Scientific and Technological Project of Henan (no. 162102310182).

\section{Conflict of interest}

No conflict of interest is associated with this work.

\section{Contribution of authors}

We declare that this work was done by the authors named in this article and all liabilities pertaining to claims relating to the content of this article will be borne by the authors.

\section{Open Access}

This is an Open Access article that uses a funding model which does not charge readers or their institutions for access and distributed under the terms of the Creative Commons Attribution License (http://creativecommons.org/licenses/by/ 4.0) and the Budapest Open Access Initiative (http://www.budapestopenaccessinitiative.org/rea d), which permit unrestricted use, distribution, and reproduction in any medium, provided the original work is properly credited.

\section{REFERENCES}

1. Bruix J, Han KH, Gores G, Llovet JM, Mazzaferro V. Liver cancer: Approaching a personalized care. J Hepatol 2015; 62(1 Suppl): S144-156.

2. Lee EY, Xuan Mai TT, Chang Y, Ki M. Trends of liver cancer and its major risk factors in Korea. Epidemiol Health 2015; 37: e2015016.

3. Mehta A, Herrera H, Block T. Glycosylation and liver cancer. Adv Cancer Res 2015; 126: 257-279.

4. Ramakrishnan R, Wahab L, Lloyd T, Wahab L, Lloyd T, Sharma $R$. Inflammation-based prognostic indices in malignant pleural mesothelioma. J Thorac Oncol 2012; 7(3): 587-594.

5. Zhao W, Ma G, Chen X. Lipopolysaccharide induced LOX-1 expression via TLR4/MyD88/ROS activated p38MAPK-NF-kappaB pathway. Vascul Pharmacol 2014; 63(3): 162-172.

6. Xu Z, Ren T, Xiao C, Li H, Wu T. Nickel promotes the invasive potential of human lung cancer cells via TLR4/MyD88 signaling. Toxicology 2011; 285 (1-2): 2530.
7. Nidhi B, Sharavana G, Ramaprasad TR, Vallikannan B. Lutein derived fragments exhibit higher antioxidant and anti-inflammatory properties than lutein in lipopolysaccharide induced inflammation in rats. Food Funct 2015; 6(2): 450-460.

8. Logsdon CD, Abbruzzese JL. Chemoprevention of pancreatic cancer: ready for the clinic? Cancer Prev Res 2010; 3(11): 1375-1378.

9. Dennis $T$, Fanous M, Mousa S. Natural products for chemopreventive and adjunctive therapy in oncologic disease. Nutr Cancer 2009; 61(5): 587-597.

10. Kewitz S, Volkmer I, Staege MS. Curcuma Contra Cancer? Curcumin and Hodgkin's Lymphoma. Cancer Growth Metastasis 2013; 6: 35-52.

11. Singh CK, Ndiaye MA, Ahmad N. Resveratrol and cancer: Challenges for clinical translation. Biochim Biophys Acta 2015; 1852(6): 1178-1185.

12. Guzman JD, Gupta A, Bucar F, Bhakta S. Antimycobacterials from natural sources: ancient times, antibiotic era and novel scaffolds. Front Biosci (Landmark Ed) 2012; 17: 1861-1881.

13. Wu HC, Cheng, MJ, Peng CF, Yang SC, Chang HS, Lin $\mathrm{CH}$, Wang CJ, Chen IS. Secondary metabolites from the stems of Engelhardia roxburghiana and their antitubercular activities. Phytochemistry 2012; 82: 118127.

14. Jacob C. Special issue: redox active natural products and their interaction with cellular signaling pathways. Molecules 2014; 19(12): 19588-19593.

15. National Research Council (US) Committee for the Update of the Guide for the Care and Use of Laboratory Animals. Guide for the Care and Use of Laboratory Animals.8th edition. Washington (DC): National Academies Press (US); 2011.

16. Van Meerloo J, Kaspers GJ, Cloos J. Cell sensitivity assays: the MTT assay. Methods Mol Biol 2011; 731: 237-245.

17. Rasch S, Algul H. A clinical perspective on the role of chronic inflammation in gastrointestinal cancer. Clin Exp Gastroenterol 2014; 7: 261-272.

18. Becze $E$. Stress and inflammation combine to fuel cancer growth. ONS connect 2014; 29(4): 30-31.

19. Yan J, Huang J. Innate gammadeltaT17 cells convert cancer-elicited inflammation into immunosuppression through myeloid-derived suppressor cells. Oncoimmunology 2014; 3(8): e953423.

20. Vlachostergios PJ, Gioulbasanis I, Ghosh S, Tsatsanis C, Papatsibas G, Xyrafas A, Hatzidaki E, Vasiliou C, Kamposioras K, Agelaki S, et al. Predictive and prognostic value of LPS-stimulated cytokine secretion in metastatic non-small cell lung cancer. Clin Transl Oncol 2013; 15(11): 903-909.

21. Conroy H, Mawhinney L, Donnelly SC. Inflammation and cancer: macrophage migration inhibitory factor (MIF)-the potential missing link. QJM 2010; 103(11): 831-836.

22. Liu L, Li YH, Niu YB, Sun Y, Guo ZJ, Li Q, Li C, Feng J, Cao SS, Mei QB. An apple oligogalactan prevents against inflammation and carcinogenesis by targeting

Trop J Pharm Res, April 2020; 19(4): 705 
LPS/TLR4 /NF-KB pathway in a mouse model of colitisassociated colon cancer. Carcinogenesis 2010; 31(10): 1822-1832.

23. Pantziarka P, Bouche G, Meheus L, Sukhatme V, Sukhatme VP. Repurposing drugs in oncology (ReDO)cimetidine as an anti-cancer agent. Ecancermedicalscience 2014; 8: 485-508.

24. Singh R, Mishra MK, Aggarwal H. Immunity, inflammation, and cancer. Mediators Inflamm 2017; 2017: 6027305.

25. Wang L, Zhu $R$, Huang $Z$, Li $H$, Zhu $H$. Lipopolysaccharide-induced toll-like receptor 4 signaling in cancer cells promotes cell survival and proliferation in hepatocellular carcinoma. Dig Dis Sci 2013; 58(8): 2223-2236.

26. Mencin A, Gwak GY, Schwabe RF. Mechanisms by which TLR4 and endotoxin promote hepatocellular carcinoma require further investigation. Hepatology 2011; 54(2): 745-746.

27. Plociennikowska A, Hromada-Judycka A, Borzecka K, Kwiatkowska K. Co-operation of TLR4 and raft proteins in LPS-induced pro-inflammatory signaling. Cell Mol Life Sci 2015; 72(3): 557-581. 